Int. J. Dev. Biol. 54: 1045-1054 (2010)

doi: $10.1387 / \mathrm{ijdb} .103062 \mathrm{tj}$

\title{
Aortic remodelling during hemogenesis: is the chicken paradigm unique?
}

\author{
THIERRY JAFFREDO*, CHARLOTTE RICHARD, CLAIRE POUGET\#, MARIE-AIMÉE TEILLET, \\ KARINE BOLLÉROT, RODOLPHE GAUTIER and CÉCILE DREVON \\ CNRS and UPMC UMR7622, Laboratoire de Biologie du Développement, Paris, France
}

\begin{abstract}
Since the era of the ancient Egyptians and Greeks, the avian embryo has been a subject of intense interest to visualize the first steps of development. It has served as a pioneer model to scrutinize the question of hematopoietic development from the beginning of the 20th century. It's large size and easy accessibility have permitted the development of techniques dedicated to following the origins and fates of different cell populations. Here, we shall review how the avian model has brought major contributions to our understanding of the development of the hematopoietic system in the past four decades and how these discoveries have influenced our knowledge of mammalian hematopoietic development. The discovery of an intra-embryonic source of hematopoietic cells and the developmental link between endothelial cells and hematopoietic cells will be presented. We shall then point to the pivotal role of the somite in the construction of the aorta and hematopoietic production and demonstrate how two somitic compartments cooperate to construct the definitive aorta. We shall finish by showing how fatemapping experiments have allowed the identification of the tissue which gives rise to the subaortic mesenchyme. Taken together, this review aims to give an overview of how and to what extent the avian embryo has contributed to our knowledge of developmental hematopoiesis.
\end{abstract}

KEY WORDS: avian embryo, hemogenic endothelium, aorta, somite, smooth muscle cells, Runx1

\section{Introduction}

Since the first reports on blood cells more than a century ago, a corpus of data has been collected on the spatio-temporal emergence and molecular control of developmental hematopoiesis. Pioneering studies addressing the emergence of the hematopoietic system were performed in the avian embryo whose large size, easy access and topology, flat on the yolk, make it highly suitable for observation and manipulation. The work was then extended to frogs and selected mammalian embryos i.e., mouse and human. Recently the bony fish Danio rerio has been increasingly used to decipher the molecular pathways involved in the development of the hematopoietic system (see Paik and Zon and Ciau-Uitz et al., this issue and references therein). In parallel to these in vivo systems, valuable insights have been obtained from embryonic stem cell cultures (Kyba and Daley, 2003; Lacaud et al., 2004; Lacaud etal., 2001; Wang et al., 2004). Taken together, these data have revealed that the developmental programmes of blood and endothelium are closely related and remarkably conserved among species and have recently unravelled some of the mechanisms giving rise to blood cells (Eilken et al., 2009; Lancrin et al., 2009). However, several questions are still pending regarding the origin(s) of definitive Hematopoietic Stem Cells (HSCs)the cells at the origin of the adult hematopoietic system. For example, the nature of the cell(s) giving rise to the definitive Hematopoietic Cell ( $\mathrm{HC})$ types during development has not yet been completely elucidated despite recent progress. Most of the current data suggest that HSCs emerge from a specific subset of Endothelial Cells (EC) that have the capacity to generate blood i.e., the hemogenic endothelium. Other data propose that HSC

\footnotetext{
Abbreviations used in this paper: EC, endothelial cell; HC, hematopoietic cell; HSC, hematopoietic stem cell.
}

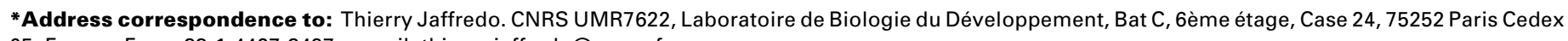
05, France. Fax: +33-1-4427-3497. e-mail: thierry.jaffredo@upmc.fr

\#Note: MRC Molecular Hematology Unit, Weatherall Institute of Molecular Medicine, University of Oxford, Oxford OX1 2JD, UK.

Final, author-corrected PDF published online: 16 July 2010.

ISSN: Online 1696-3547, Print 0214-6282 
emerge de novo from mesenchymal cells. This review aims to give an overview of the development of the hematopoietic system in the avian model and to discuss data obtained in this species regarding the origins of HSCs in relationship with the aorta.

\section{The embryo harbours the source for definitive HSCs}

Based on observations collected more than a century ago on avian embryos, it was proposed that the yolk sac was pivotal in the production of HCs. Early yolk sac-associated hematopoiesis mainly gives rise to erythroid cells easily visible because of the presence of hemoglobin. However during the same period, several authors reported the presence of cells, interpreted as being hematopoietic, associated with the ventral aspect of the embryonic aorta. Fifty years later, the role of the yolk sac in the production of HCs was analyzed through a series of experiments conducted by Moore, Owen and Metcalf (Moore and Owen, 1965; Moore and Owen, 1967a). According to these authors, HSCs were all produced in the yolk sac at an early stage and subsequently migrated to the hematopoietic organ rudiments, i.e., the fetal liver, spleen, thymus and bone marrow. Thus, the hematopoietic organs were colonized by yolk sac-derived cells, the bone marrow being the life-long reserve (Moore and Owen, 1967b). Soon after this view was proposed and considered as reliable, $\mathrm{F}$. Dieterlen and co-workers initiated a series of experiments challenging the yolk sac origin. Based on the use of the quail/chick system (Le Douarin, 1969), they grafted a quail embryo on a chick yolk sac (Martin, 1972), an experimental scheme designated as "yolk sac chimera" (Dieterlen-Lievre, 1975). Contrary to the centripetal flow of HCs postulated by Moore and Owen, hematopoietic organs were seeded exclusively by quail cells that even colonized the yolk sac by embryonic day (E)5 (Beaupain et al., 1979; Martin et al., 1978). On E13, as much as $70 \%$ of circulating blood cells were of quail origin in some chimeras (Beaupain et al., 1979). Similar associations between congenic strains of chickens differing either by their sex chromosomes (Lassila et al., 1978), their immunoglobulin haplotypes (Lassila et al., 1979; Martin et al., 1979) or major histocompatibility antigens (Lassila et al., 1982) led to even more striking conclusions. HCs of yolk sac origin decreased rapidly from E5 and disappeared by hatching. Thus, yolk sac progenitors had proved incapable of long-term renewal and the source of "definitive" HSCs colonizing the hematopoietic organs was shown to originate from the embryo proper (for a comprehensive view of avian yolk sac hematopoiesis see Cheng et al., this issue).

Aiming to identify the intra-embryonic site(s) where adult-type HCs were produced, Dieterlen-Lièvre and co-workers focused on cell clusters, tightly associated with the ventral aspect of the aorta protruding into the aortic lumen described early on (see DieterlenLievre et al., 2006 for a review). Their hematopoietic nature was confirmed by means of the MB1/QH1 (Pardanaud et al., 1987) and anti-CD45 (Jeurissen and Janse, 1998) antibodies. The aortic region, also designated in mammals as the Psp/AGM (Para-aortic Splanchnopleura/ Aorta-Gonad-Mesonephros) i.e., the aorta and the surrounding tissues at two successive stages of development, was shown to harbour cells giving rise to erythroid, monocytic, myeloid or multipotential colonies (Cormier, 1993; Cormier et al., 1986; Cormier and Dieterlen-Lievre, 1988) as well as transplantable HSCs (Lassila et al., 1980).

\section{Intra-aortic clusters}

The demonstration of an intra-embryonic source of HSC by the complementary chimeras has prompted investigators to seek site(s) that may harbour HCs. As early as the beginning of the 20th century, several investigators had reported the existence of small clusters of cells firmly attached to the ventral wall of the aorta in various embryo species (see Dieterlen-Lievre et al., 2006 and references therein). These intra-aortic clusters have a feature common to all species investigated; they are restricted to the ventral aspect of the aortic endothelium and they also extend to the vitelline arteries where they display the same ventral polarization (de Bruijn et al., 2002; Garcia-Porrero et al., 1995; Marshall et al., 1999; Tavian et al., 1996; Wood et al., 1997). As an exception to this rule, the mouse embryo has been reported recently to harbour a few small hematopoietic clusters on the dorsal aspect of the aorta. Functional tests indicated that these dorsal clusters are composed of multipotent hematopoietic progenitors but did not contain HSCs (Taoudi and Medvinsky, 2007). In the chick embryo, the intra-aortic clusters appear soon after the two aortic anlagen fuse to form the dorsal aorta. They display several interesting features that allow the identification of discrete steps in the initiation and maturation of the clusters; i) clusters are found all along the trunk region except in it's anterior- and posterior-most aspects; ii) hematopoiesis extends over the whole aortic floor and displays a latero-medial progression i.e. hematopoiesis begins in the lateral aspect of the vessel and progressively reaches the medial part; iii) the cephalo-caudal development combined with the relatively slow avian development makes possible to identify several key cellular and molecular steps in cluster formation. Three distinct steps can be recognized. First, the hemogenic endothelium stage, is characterized by the presence of a, still flat, ventral endothelium, a low expression of CD45 in cells that have retained an endothelial phenotype (Fig. 1A) and a prominent expression of runx1 (Fig. 1B). A thick endothelium stage follows wherein the hemogenic ECs loose their flat phenotype, display a more cuboidal shape and a reinforced expression of CD45 and runx1(Fig. 1 C,D). Finally, the hematopoietic cluster stage is characterized by the budding of $\mathrm{HCs}$ and the prominent expression of CD45 and runx1 (Fig. 1 E,F). The hematopoietic nature of cells in the clusters is testified by the expression of the pan-leukocytic antigen CD45 (Jaffredo et al., 1998); a feature shared with mammalian species (Manaia et al., 2000; Marshall et al., 1999; Tavian et al., 1996). Furthermore, these cells express the CD41 antigen or $\alpha$ llb integrin subunit while ECs express CD51 or the $\alpha \mathrm{V}$ integrin subunit. The CD41 integrin, was adopted as a diagnostic tool for HSCs, on the basis of its striking expression by the intra-aortic clusters in the chicken (Ody et al., 1999) and the mouse (Corbel, 2002). It is now used as a hallmark of HSCs in the fetus (Emambokus and Frampton, 2003; Mikkola et al., 2003). The endothelial-specific $\alpha \mathrm{V}$ integrin subunit (CD51) and the hematopoietic-specific CD41 display complementary patterns in the dorsal aorta of the chick embryo.

On the whole, cluster cells in the avian embryo share many surface proteins with ECs and express many common transcription factors although several molecular features other than CD41 make it possible to distinguish the clusters from the endothelium. The hematopoietic clusters are sharply demarcated from EC by the expression of transcription factors $c$-myband runx 1 (a marker 
of hemogenic endothelium and embryonic HSC), the pan-leukocyte CD45 antigen and by the disappearance of VEGF-R2 (Bollerot et al., 2005; Jaffredo et al., 1998) and ve-cadherin (Jaffredo et al., 2005).

In order to elucidate the origin of the peculiar cell disposition of the clusters, it appeared necessary to trace the fate of the ventral endothelium and to establish the developmental history of the aorta.

\section{Dynamic tracing of the hemogenic endothelium in birds}

As early as 1916, Jordan proposed that the intra-aortic clusters originated from the aortic ECs (Jordan, 1916). We have investigated the fate of aortic ECs by tagging the aortic endothelium with two vital tracers, either Acetylated Low Density Lipoprotein (AcLDL) coupled to a fluorescent lipophilic marker (Dil) or a non-replicative retroviral vector carrying a reporter gene. AcLDL-Dil has three major advantages: i) it is specifically endocytosed by EC and macrophages (the latter still absent at the stage of inoculation) by a specific receptor; ii) it labels all ECs; iii) it has a short half-life meaning it disappears from circulation if not immediately endocytosed. The use of retroviral vectors allows stable expression of the reporter gene for extended periods of time. While it permits to identify the entire progeny of labelled EC, it also allows the identification of clones because integration occurs only in sparse cells. Both tracers were inoculated into the heart, ensuring direct contact with the endothelium lining the vessels, at early E2, one day before the emergence of the aortaassociated HCs. Aorta-associated cells were identified with the anti-VEGF-R2 (Eichmann et al., 1997) and anti-CD45 antibodies (Jeurissen and Janse, 1998) as EC and HC probes, respectively.

As early as 2 hours after AcLDL-Dil inoculation, the whole vascular tree was labelled. The aortae, still paired at that time, were entirely lined by AcLDL-Dil ${ }^{+}$ECs, while no $C D 45^{+}$cells were present in or around the aorta or in the circulation. One day after inoculation, when hematopoietic clusters emerged, all cells therein were AcLDL-Dil ${ }^{+}$CD $45^{+}$. Interestingly AcLDL$\mathrm{Dil}^{+} / \mathrm{CD} 45^{+}$double-positive cells were also found in the mesenchyme ventral to the aorta, suggesting that a subset of $\mathrm{HCs}$ had ingressed into this region from the ventral endothelium (Jaffredo et al., 1998). Moreover, after retroviral labelling, the hemato-

Fig. 1. Three steps of hematopoietic cell differentiation in the aorta (cross sections). (A,B) Hemogenic endothelium stage. (C,D) Thick endothelium stage. (E,F) Hematopoietic cluster stage. Level of the 15th somite. Left column CD45 immunostaining, right column runx1 in situ hybridization. (A,B) HH17. The paired aortae have fused recently. CD45 (A) is expressed in cells that retain a flat phenotype (white arrowhead) or have already acquired a round phenotype (white arrow). Runx 1 is expressed by all cells of the aortic floor. Most of them retain a flat, endothelial phenotype. (C,D) HH19. Hematopoiesis is now prominent. Hemogenic ECs have lost their flat phenotype to a more cubic aspect. Note that the runx 1 pattern extends more laterally than the CD45 pattern. (E,F) HH21. Hematopoietic clusters have formed. They are typically arranged as two, symmetric rows of cells. The burgeoning aspect is now prominent. A, aorta; $C$, coelom; CV, cardinal vein; $N$, notochord; NT, neural tube. poietic foci that develop in the mesenchyme ventral to the aorta contained numerous lac $Z^{+}$cells. These foci, characteristic of the chicken are a site of diffuse hematopoiesis. They develop between E5 and E9 forming large aggregates of cells immediately underneath the aorta. Thus a developmental relationship exists between intra-aortic clusters and para-aortic foci, the latter being seeded by progenitors derived from the E3 aortic floor (Jaffredo et al., 2000).

We conclude that, in the avian embryo, during the first week of development, intra-embryonic progenitors derive from the aortic floor through a unique process that switches the phenotype of cells previously contributing to the endothelial lining of the aorta. Of note, the endothelial origin of hematopoietic clusters in the mouse embryo has been recently investigated using the VE-Cadherin CRE mouse wherein the CRE recombinase is specifically expressed by ECs (Zovein et al., 2008; see also Oberlin and Souyri, this issue). A large number of HCs including HSCs were shown to derive from an endothelial intermediate. At the level of the aorta, the comparison
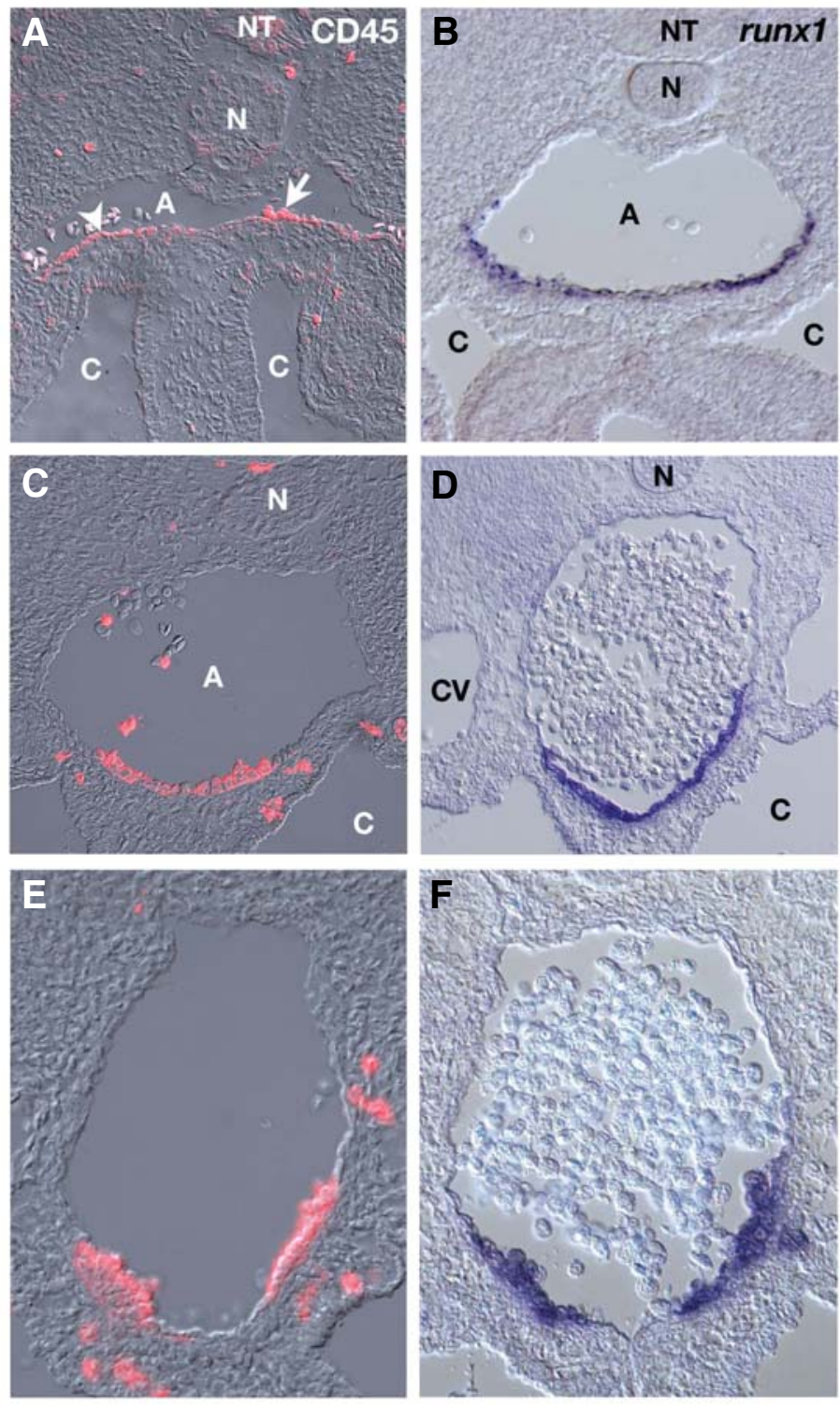
between VE-Cadherin CRE and Myocardin CRE, the latter labelling cells around the aorta with the exception of the endothelium, clearly demonstrated that the hematopoietic clusters originated from the endothelium (Chen et al., 2009; Zovein et al., 2008), thus confirming the data obtained on the chick embryo.

\section{The somite, a major actor in the construction of the aorta}

The embryonic mesoderm, i.e., the germ layer which gives rise - among other derivatives - to the blood system, arises during gastrulation as a single sheet; it then divides rostro-caudaly into several medio-lateral components that are the somite, the intermediate mesoderm and the lateral plate which is itself divided into two layers, a dorsal one designated as the somatopleural mesoderm and the ventral one designated as the splanchnopleural mesoderm. The respective contributions of these components to the blood/vascular system were established through a series of experiments implementing quail/chicken graftings of organ rudiments. To summarize, limb buds (somatopleural derivatives) were shown to become vascularized by exogenous angioblasts (Pardanaud et al., 1989), by a process known as angiogenesis (Risau and Lemmon, 1988), while viscera (splanchopleural derivatives) form their vascular network from their own mesoderm, a process designated as vasculogenesis (Pardanaud et al., 1989). This dual mode of blood vessel development has recently been confirmed in the mouse model (Pudliszewski and Pardanaud, 2005).

It is now admitted that somites give rise to angioblasts, highly motile cells able to migrate in every direction. This production, first shown in the chick (Noden, 1989; Pardanaud and Dieterlen-

Fig. 2. Contribution of the somite to the formation of the aorta. $\mathrm{QH} 1$ immunofluorescence (A-C) overlaid with Nomarsky's interferential contrast. (D) QH1/OCPN immunohistochemistry. (A) 24 hours after right somite grafting. The roof of the right aortic rudiment is colonized by $\mathrm{QH} 1+\mathrm{EC}$ s (arrowhead). QH1 + cells around the neural tube organize into the perineural plexus. A few $\mathrm{QH} 1+$ cells contribute to the cardinal vein whereas some others have migrated in the limb bud rudiment. (B) 30 hours after grafting. The roof and side of the aorta are entirely of quail origin on the grafted side. Some quail EC and angioblasts are scattered lateral to the aorta. (C) 48 hours after grafting. Somite-derived ECs have now invaded the floor of the aorta. Some Quail ECs have integrated the endothelial layer whereas some others are found scattered underneath the clusters that are of chick origin. The bottom right insert is a higher magnification of the frame in C. ECs of somitic origin are positioned immediately underneath the hematopoietic clusters which are of chick origin. (D) 4 days after grafting. The $\mathrm{QH} 1+$ cells have formed a conspicuous plexus around the neural tube. Vascularization of the dermis is also clearly visible. The roof and side on the grafted region as well as the floor are now entirely of quail origin (arrowheads). L, limb bud; $M$, mesonephros.
Lievre, 1993; Wilting et al., 1994), was recently demonstrated to take place in the mouse embryo (Ambler et al., 2001; Ema et al., 2006). To demonstrate that somites might be the source of angioblasts colonizing the somatopleural mesoderm, the lastformed one or two somites were transplanted orthotopically from the quail into the chicken. Endothelial precursors from the somite migrated in the body wall, kidney and limbs (Pardanaud et al., 1996). Somite-derived angioblasts also integrated into the roof and sides of the aortic endothelium forming a mosaic vascular network with the EC of the host but never penetrated into visceral organs nor integrated into the aortic floor up to E3, the latest stage examined whereas angioblasts derived from quail splanchnopleural mesoderm, grafted on top of the host splanchnopleura, also migrated out but invaded all embryonic territories, i.e, the limb bud and body wall, visceral organs but also the floor of the aorta wherein they gave rise to intra-aortic clusters. Thus the somite-derived angioblasts and splanchnopleura-derived angioblasts have distinct homing potentials and the homing site is a second requirement for the emergence of clusters. To summarize, the body wall (somatopleural mesoderm), unable by itself to make blood vessels, becomes vascularized by angioblasts emigrating from the somites, while the splanchnopleural meso-
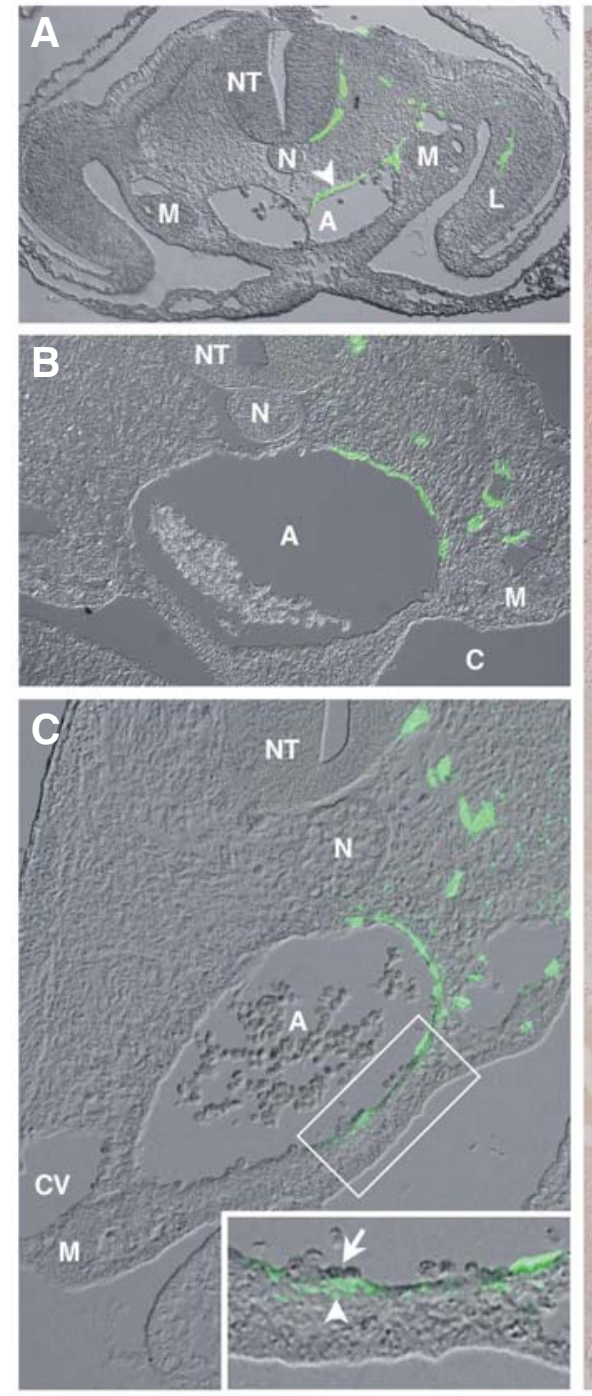

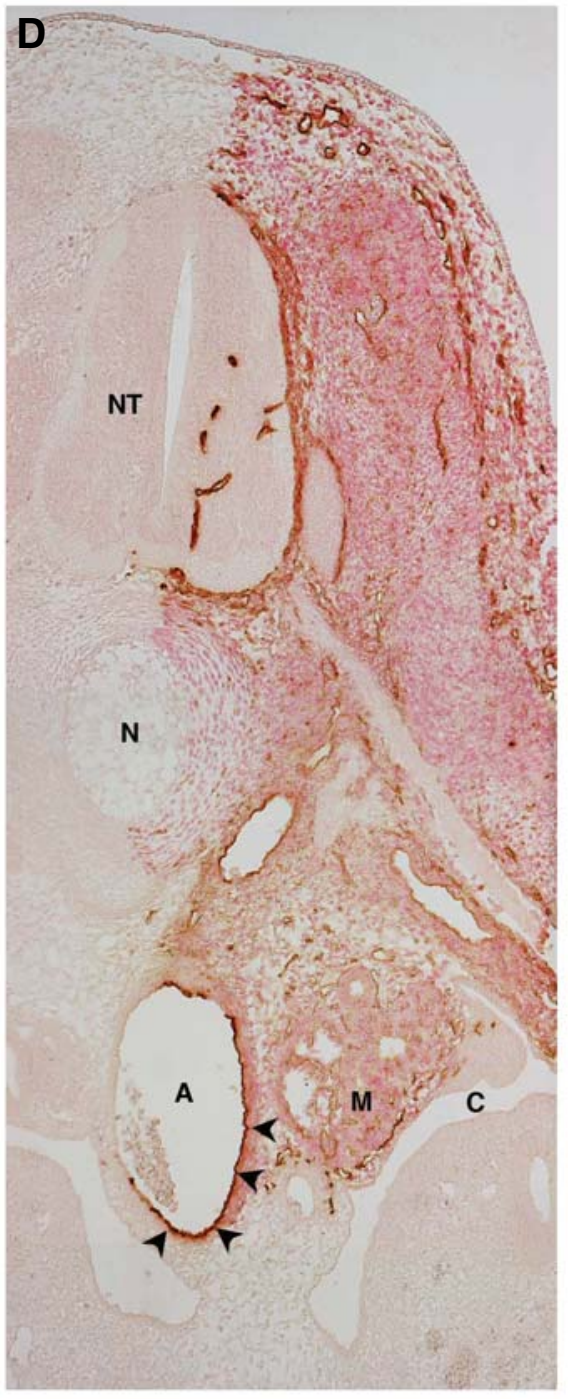


derm gives rise to angioblasts that are able to convert into HCs.

Using a revised version of the somitic grafts, we have recently obtained a dynamic view of aortic evolution (Pouget et al., 2006); In this approach, the grafted material involved the whole segmental plate (approximately the 10 future somites) plus the last segmented somite and the host embryos were examined at different time points. Quail somitic cells invaded the roof of the chicken aorta around 15 hours after grafting at the time the aortic anlagen were still paired (Fig. 2A). At 24 hours, only the aortic floor and the clusters were chicken (host), i.e., splanchnopleural, in origin (Fig. 2B). After the clusters formed and disappeared, the floor became progressively quail, i.e., derived from the grafted somitic material (Fig. 2 C,D). As a result, the endothelium of the definitive aorta at E4-4.5 was entirely composed of somitederived cells (Fig. 2D). Since somite-derived angioblasts were not endowed with the capacity to give rise to blood, the hematopoietic production ceased. The inability of somitic angioblasts to penetrate into the viscera was confirmed in this model, despite the replacement of long strips of somitic material.

These experiments shed an interesting light on the problem of the developmental relationships between endothelium and $\mathrm{HCs}$, showing that the aortic floor endothelium is a temporary structure which becomes spent and replaced as hematopoiesis ceases. In addition, they provide an explanation for the briefness of the intraaortic cluster production, a feature observed in all the species studied so far; hematopoietic production depends on a limited, non-renewable, pool of hemogenic EC.

How is this dorsal vs ventral EC homing established? Experiments involving treatment of somites or splanchnopleural meso-

Fig. 3. Contribution of dermomyotome and sclerotome to the fortmation of the aorta. (A-D) Grafts of single dermomyotome analysed at $24 h(\mathbf{A}, \mathbf{B})$ and $48 h(\mathbf{C}, \mathbf{D})$ post-grafting. (E-H) Grafts of single sclerotome $\mathbf{( E , H )}$ analysed at $24 h(\mathbf{E}, \mathbf{F})$ and $48 h(\mathbf{G}, \mathbf{H})$ post-grafting. $(\mathbf{A}, \mathbf{C}, \mathbf{E}, \mathbf{F})$ QCPN immunodetection. (B,D) Triple QH1 (red), aSMA (green) and DAPI (blue) staining. (G,H) Double OCPN (red) and $\alpha S M A$ (green) staining. (A) At 24h post-graft, the quail dermomyotome is organized including the epaxial and hypaxial lips. (B) Quail ECs are found around the neural tube organizing into the perineural plexus. A single EC is found in the roof of the aorta. At this stage the vascular wall has already begun to assemble around the aorta except in the dorsal-most aspect of the vessel (no $\alpha S M A$ signal). Note that the myotome also expresses $\alpha S M A$, an early marker of skeletal myogenic cells (Sassoon et al., 1988). (C) The dermomyotome has elongated ventrally. No OCPN+ cell is found around the aorta. (D) The vascular wall is now complete and shows robust $\alpha S M A$ expression. The grafted dermomyotome has provided ECs that have organised into a vascular plexus around the neural tube on the grafted side. ECs being endowed with extensive migratory capacities, when only one somite is grafted, or as here, only the dermomyotome from one somite, they disperse along a large segment of aorta so that EC from graft origin are very sparse and eventually do not integrate in the aortic roof. (E) 24 hours after sclerotome graft. The grafted $O C P N+$ compartment is restricted to the medial-most sclerotome on the grafted side. (F) Higher magnification of the frame in (E). $Q C P N+$ cells are in close apposition to ECs which are from host origin. Note that a few pioneer quail cells have migrated along the aorta on the grafted side. (G) Double immunohistochemistry with QCPN and $\alpha S M A$ antibodies on the same section respectively revealed in red and green. Two days after the graft. The grafted QCPN compartment has extended ventrally. The wall of the aorta is made of $\alpha S M A+$ cells. The dermomyotome is also positive for $\alpha S M A$. (H) Higher magnification of the frame in G shows QCPN+/ aSMA+ cells forming the aortic wall. derm from quail with growth factors followed by transplantation into a chick host have revealed the existence of molecules and tissues triggering the angioblasts contribution to the somatopleural or splanchnopleural mesoderm. When the quail somites were cultured for 12 hours in association with endoderm, or in the presence of VEGF (Vascular Endothelial Growth Factor), bFGF (basic Fibroblast Growth Factor) or TGF $\beta$ (Transforming Growth Factor $\beta$ ), somite-derived angioblasts acquired the ability to integrate into the aortic floor and to adopt the hematopoietic
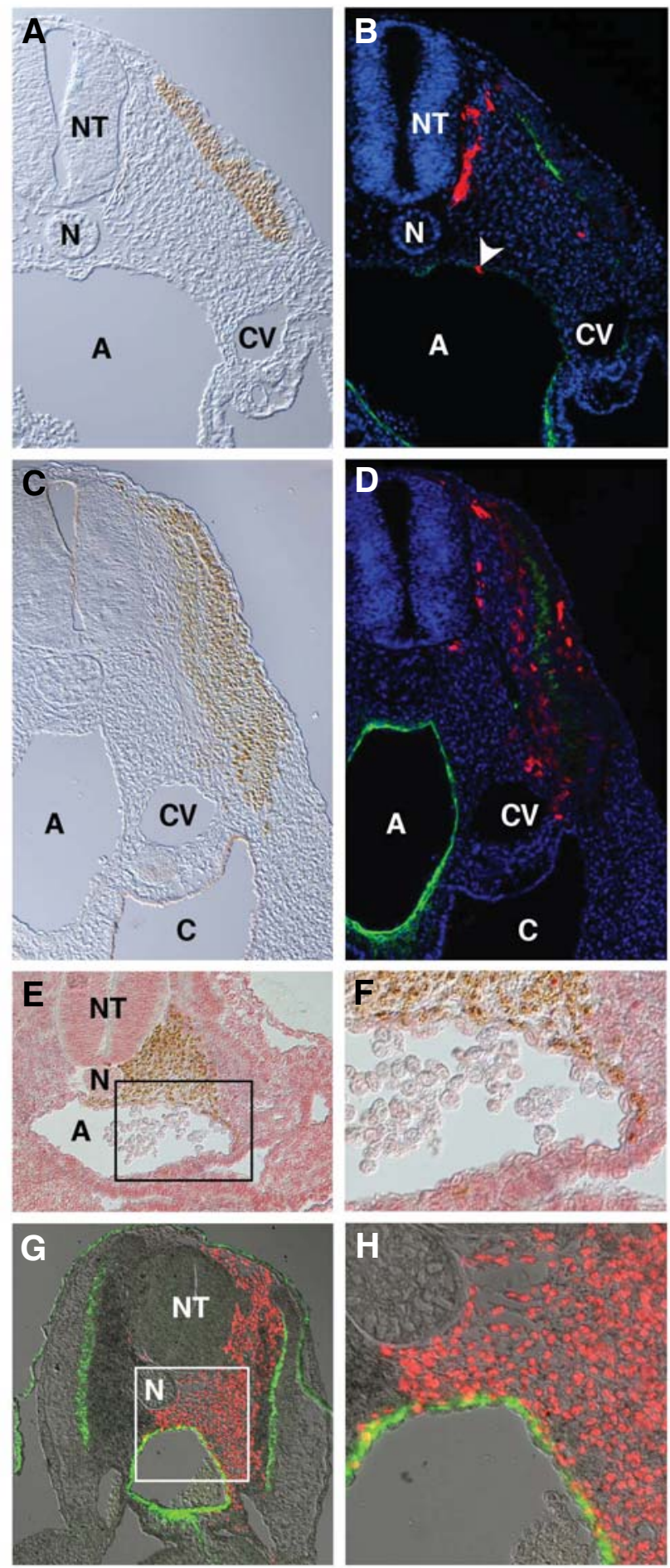
A
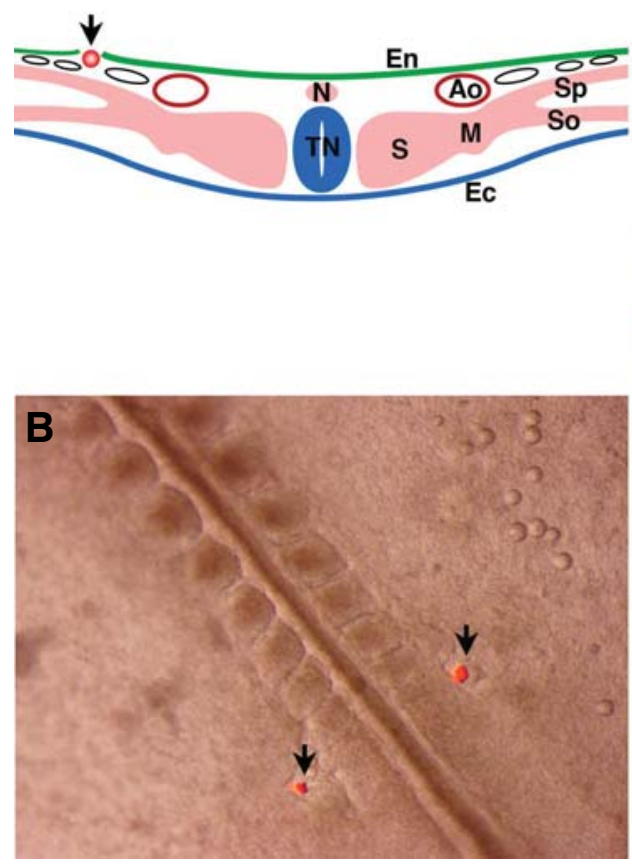
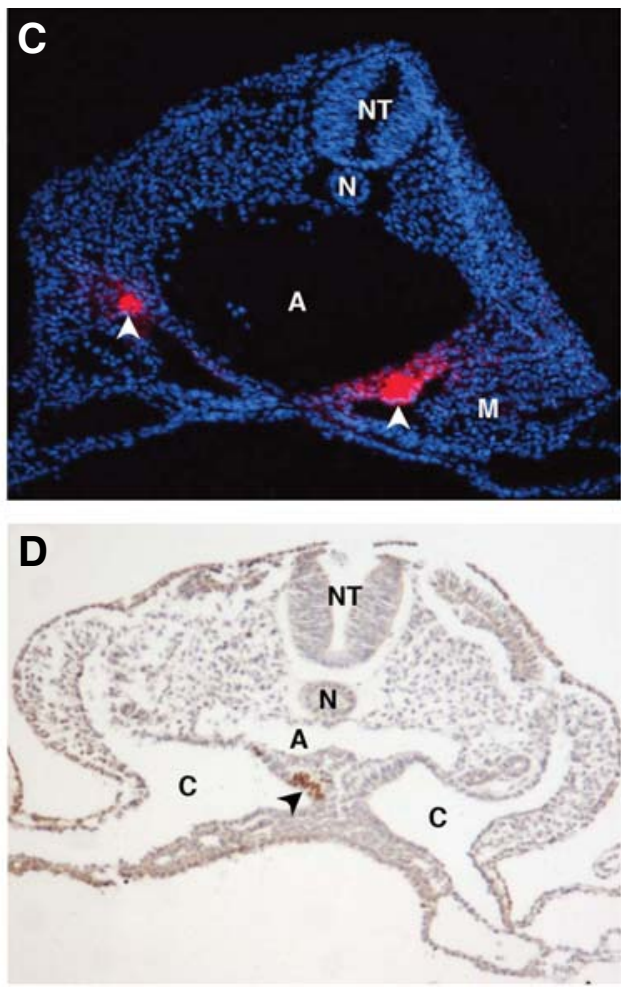

Fig. 4. Mapping of the sub-aortic mesenchyme using Dil labelling and quail-chick grafting. (A) Schematic representation of the Dil labelling. Embryos staged between 10 and 14 somite pairs are placed ventral side up on a Petri dish covered with a 50-50 mix of thin albumen and PBS. A small hole is made in the endoderm (green) and the Dil crystal (arrow) is deposited onto the splanchnopleural mesoderm (sp). The embryo is incubated for an additional period of one to two days. (B) 10 to 12somite embryo with a bilateral deposition of Dil (arrows). The crystals are placed at the level of the last formed somites. (C) Cross section of an embryo submitted to a bilateral deposition of Dil $250 \mu \mathrm{m}$ to the midline one day before. The red stain is found immediately underneath the aorta (white arrowheads). (D) Chick embryo grafted with quail splanchnopleural mesoderm on the left side. Quail cells are revealed with the QCPN monoclonal antibody. Grafted quail cells have migrated towards the midline and settled underneath the aorta.

phenotype. Thus the potential to home to this location was conferred by the pre-treatment, and the existence of a second requirement to give rise to hematopoiesis was confirmed despite this second signal was yet to be identified. The BMP family of growth factors is well established as ventralizing factors and was recently demonstrated to be major signalling pathway during the production of HSCs (Durand et al., 2007; Robin and Durand, 2010), yet, pre-treatment of somitic mesoderm with BMP 4 did not confer the ability to home to the aortic floor (Pardanaud and Dieterlen-Lievre, 1999). The paradoxical inefficiency of BMP in this particular set up might be due to a mistimed treatment. Conversely, pre-treatment of splanchnopleural mesoderm with ectoderm, EGF (Ectodermal Growth Factor) or TGF $\alpha$ (Transforming Growth Factor alpha) precluded the homing of derived cells to the aortic floor (Pardanaud and Dieterlen-Lièvre, 1999). It is clear from the experiments mentioned above that ectoderm, endoderm or growth factors mimicking the effect of the germ layers are able to instruct ECs to trigger either a ventral (hemogenic) or a dorsal (non-hemogenic) fate. The precise signals that implement these potentials should be worked out in the future. Two different and complementary requirements for ECs to reach the aorta were recently demonstrated using the chicken embryo. EphrinB2 was shown to be sufficient to drive somite ECs to the aorta but Notch activation appeared necessary for ECs to respond to EphrinB2 signalling (Sato et al., 2008). It remains to be determined if such a mechanism exists in the mammalian embryo.

\section{Dermomyotome and sclerotome contributions}

The quail-chick grafting experiments also revealed that the somite contributes to another aortic lineage, that is, the smooth muscle. Vascular Smooth Muscle Cells (vSMC), as revealed by the expression of the $\alpha$ Smooth Muscle Actin $(\alpha S M A)$ protein, begin to differentiate around the aorta at the time of hematopoietic cluster production and continue after hematopoiesis has ceased. At the time we published this study (Pouget et al., 2006), another paper reported that the dermomyotome, which later on provides dermis and striated muscles, may harbours a common $\mathrm{Pax}^{+}$progenitor for smooth muscle and EC in the mouse embryo (Esner et al., 2006).

Aiming to investigate this question, we analyzed the sub-somitic origin of the vSMCs and ECs in the avian embryo. Quail-chick orthotopic transplantations of the dorsal or ventral half from a single somite were performed. The dorsal half corresponds to the future dermomyotome whereas the ventral half corresponds to the future sclerotome. Grafts have been analysed with QCPN, an antibody recognizing all quail cells, QH1 quail HC- and EC-specific (Pardanaud et al., 1987) and 1A4, a monoclonal antibody recognizing the alpha smooth muscle actin protein. In some cases, in situ hybridization with Pax3 or Pax1 probes respectively specific for the dermomyotome and the sclerotome was combined with these antibodies. Replacing the dorsal half results in the production of quail striated muscles and ECs. However, no or very rare quail cells were found in the vicinity of the aorta (Fig. 3 A,B,C,D). The fact that very few quail cells were observed following dermomyotome grafting is attributed to the high dispersion of grafted ECs and the low number of ECs carried by the structure. Replacing the ventral half of the somite results in the production of cells migrating in close apposition to aortic ECs (Fig. $3 \mathrm{E}, \mathrm{F}$ ). The sclerotomal compartment contributes to the dorsal wall of the aorta but some single cells were rapidly found in the ventral part of the aorta suggesting that cells are able to leave the sclerotome early during somite formation (Fig. 3E). No $\mathrm{EC}$ were generated from the sclerotome. The sclerotome is the somite compartment that gives rise to vSMCs. Pax1, a molecular marker of the sclerotomal compartment, is expressed by vSMCs during the earliest phases of vascular wall formation (Pouget et 
al., 2008). Double positive QCPN (a pan-quail marker)- $\alpha$ SMA cells were clearly visible following sclerotome graft (Fig. $3 \mathrm{G}, \mathrm{H}$ ). In contrast, the dermomyotome gives rise to angioblasts but never to cells of the vascular wall (Pouget et al., 2008). Interestingly, another paper using similar quail-chick grafts approaches reached the same conclusions (Wiegreffe et al., 2007). Taken together, these data point out to the critical role of the somite in vessel formation and demonstrate that vSMCs and ECs originate from two independent somitic compartments. A striking question in the formation of the aortic vSMCs is that the very first $\alpha$ SMA-positive cells appear in the ventral aspect of the aorta. This is in contradiction with the prominent role of the sclerotome, a dorsal structure, in giving rise to vSMCs of the aorta. Using lineage-tracing approaches, (Wasteson et al., 2008) have revisited aortic vSMCs formation in the mouse embryo. The ROSA26 reporter mouse was crossed to either Hoxb6-CRE or Meox-CRE mice, so that lateral plate mesoderm cells or somitic cells were labelled respectively. The authors showed that, at the earliest stages of aorta formation, a first generation of ventral VSMC was issued from the lateral plate mesoderm, however these cells were rapidly chased ventrally by a new generation of VSMCs originating from the somite, then when aortic vSMCs formation was completed, the whole tunica of vSMCs originated from the somite. Similar conclusions were recently drawn using the quail-chick system (Wiegreffe et al., 2009).

\section{Origin and fate of the sub-aortic mesenchyme}

Based on the expression of several members of the TGF $\beta$ family in the mesenchyme ventral to the aorta, it has long been hypothesized that this tissue may play a critical role in the induction and maintenance of aorta-associated hematopoiesis. This notion is substantiated by the isolation, from the AGM, of several cell lines able to support the growth of HSCs (Oostendorp et al., 2002a; Oostendorp et al., 2002b; Oostendorp et al., 2005). Despite intense interest, the origin of the sub-aortic mesenchyme remains elusive, probably because this tissue is not amenable to manipulation in mammalian embryos. Given the ventral position of this tissue, we hypothesized that it originated from the
A

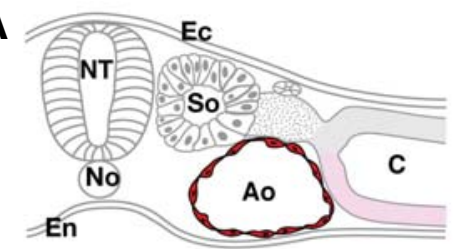

B

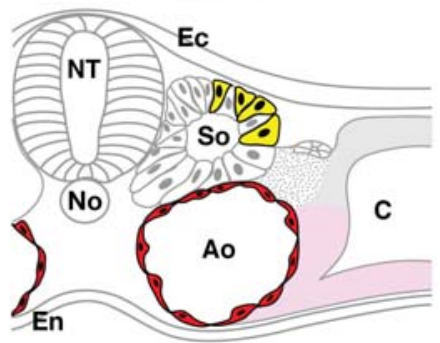

C
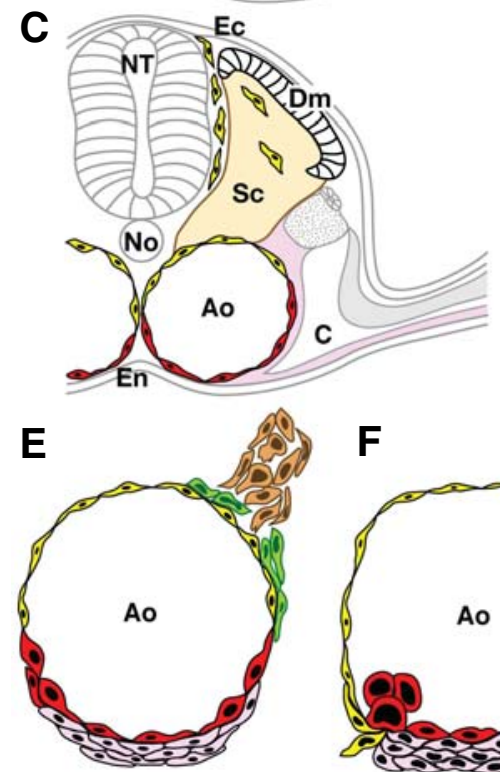

D

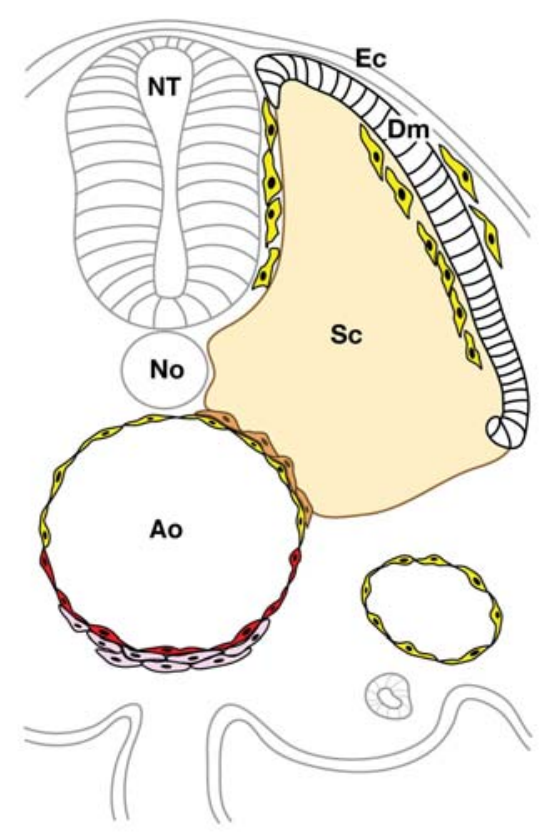

Fig. 5. Developmental history of the aorta in relation to endothelial remodelling and smooth muscle formation. (A) Before fusion of the aortic anlagen. Aortic EC (red) derive from the splanchnopleural mesoderm. As the embryo develops, the splanchnopleural mesoderm (pink) is folding and comes in close contact with the lateral part of the aortic rudiment. (B) Before fusion of the aortae. Folding of the splanchnopeural mesoderm around the aorta proceeds. Splanchnopleure-derived cells insinuate between the ventral aspect of the aorta and the endoderm, separating the two tissues. The dorso-lateral quadrant of the somite displays a population of EC (yellow). (C) Immediately before fusion. Cells of the splanchnopleural mesoderm keep on separating the ventral aspect of the aorta from the endoderm. EC of the initial roof of splanchnopleural origin (red) has been replaced by EC from the somite (yellow). At the same time, the ventral sclerotome comes in close contact with the roof of the aorta. (D) After fusion. The aortic roof is now of somite origin, the sides and floor remain of splanchnopleural origin. Splanchnopleural mesoderm-derived cells have now formed a new tissue immediately underneath the aorta (pink) that expresses smooth muscle actin. Some cells of the ventral sclerotome (brown) come in close contact with the EC of the aortic roof (Pouget et al., 2008; Wiegrieffe et al., 2007). (E) Early hematopoiesis. EC of the aortic floor begin to loose endothelial markers and acquire hematopoietic traits (from Jaffredo et al., 1998). The mesenchyme underneath the aorta now forms a continuous layer of cells expressing smooth muscle actin (Pouget et al., 2008; Wiegrieffe et al., 2007; 2009). Sclerotomal cells directly contacting the roof and sides of the aorta begin to express the smooth muscle actin protein (green) whereas more distant cells do not (brown). (F) Hematopoietic clusters stage. Clusters are budding into the lumen. At the same time, somitic EC begin to replace the initial floor. Numerous somitic EC are found in the floor underneath the clusters. Sclerotome-derived smooth muscle cells migrate more ventrally (green). (G) Completion of hematopoiesis. The initial aortic floor has disappeared and is replaced by somitic EC. Aortic EC are entirely of somite origin. Sclerotome-derived smooth muscle cells now form a continuous layer around the aorta. The initial ventral tissue originating from the splanchnopleural mesoderm has been displaced ventrally (Wasteson et al., 2008; Wiegreffe et al., 2009)). Ao, aorta; C, coelom; Dm, dermomyotome; Ec, ectoderm; En, endoderm; No, notochord; NT, Neural tube; Sc, sclerotome; So, somite. 
splanchnopleural mesoderm. Using deposits of Dil crystals on the splanchnopleural mesoderm at different distances along the medio-lateral axis, we were able to analyze the contribution of the labelled cells to the formation of the sub-aortic mesenchyme (our unpublished results). Labelling was performed in embryos cultured according to (Chapman et al., 2001). In this technique the embryo is placed ventral side up so that the splanchnopleural mesoderm is readily amenable to manipulation (Fig. 4 A,B). After Dil labelling, the embryos were placed back to the incubator for $24 \mathrm{~h}$ and analyzed on section for the presence of Dil+ cells. Dil crystals were deposited on 10 to 13-somite stage embryos at the level of the last-formed somite (Fig. 4B). At this stage, the aortae are paired and Dil crystals were deposited lateral to the vessel on both sides. When the crystals were placed $250 \mu \mathrm{m}$ from the midline or around that distance, tagged cells were found immediately underneath the aorta $24 \mathrm{~h}$ later (Fig. 4C). Deposition further than $300 \mu \mathrm{m}$ from the axis resulted in staining of the digestive tract. Similar results were obtained with grafts of quail splanchnopleural mesoderm into a chick host (Fig. 4D). These studies reveal the origin of the sub-aortic mesenchyme and unravel a precise medio-lateral allocation of the splanchnopleural mesoderm to the formation of the ventral structures in particular to the digestive tract. A comprehensive scheme recapitulating the different steps in the formation of the aorta is shown in Fig. 5.

\section{Conclusion}

During the last four decades, the avian embryo has become a major actor in the understanding of embryonic hematopoiesis. The contribution of the avian embryo model was pivotal in revealing the critical role of the embryonic compartment and the aorta in the generation of adult type HSCs, thereafter demonstrated in the mouse and human embryo (Godin et al., 1993; Medvinsky et al., 1993; Tavian et al., 1996). It has also pointed to the allantois as a new hematopoietic organ (Caprioli et al., 1998; Caprioli et al., 2001) a finding confirmed in the mouse embryo (Alvarez-Silva et al., 2003; Corbel et al., 2007; Gekas et al., 2005; Ottersbach and Dzierzak, 2005; Zeigler et al., 2006) and very recently in the human embryo (Barcena et al., 2009; Robin et al., 2009). Finally it has allowed demonstrating the role of the somite in shaping the aorta and controlling hematopoiesis. We feel confident that it will continue to yield significant insights in the future into the question of hematopoietic development.

\section{Acknowledgements \\ We would like to thank DrF. Dieterlen-Lièvre and R. Blewitt for critical reading of the manuscript. We are grateful to $S$. Gournet for excellent photographic and drawing assistance. C.R. is a recipient of the French Ministery of Research and Higher Education. This Research was funded by CNRS, UPMC and ARC-INCA Grants.}

\section{References}

ALVAREZ-SILVA, M., BELO-DIABANGOUAYA, P., SALAUN, J. and DIETERLENLIEVRE, F. (2003). Mouse placenta is a major hematopoietic organ. Development 130: 5437-5444.

AMBLER, C.A., NOWICKI, J.L., BURKE, A.C. and BAUTCH, V.L. (2001). Assembly of trunk and limb blood vessels involves extensive migration and vasculogenesis of somite-derived angioblasts. Dev Bio/234: 352-364.

BARCENA, A., KAPIDZIC, M., MUENCH, M.O., GORMLEY, M., SCOTT, M.A.,
WEIER, J.F., FERLATTE, C. and FISHER, S.J. (2009). The human placenta is a hematopoietic organ during the embryonic and fetal periods of development. Dev Bio/327: 24-33.

BEAUPAIN, D., MARTIN, C. and DIETERLEN-LIEVRE, F. (1979). Are developmental hemoglobin changes related to the origin of stem cells and site of erythropoiesis? Blood 53: 212-225.

BOLLEROT, K., ROMERO, S., DUNON, D. and JAFFREDO, T. (2005). Core binding factor in the early avian embryo: cloning of Cbfbeta and combinatorial expression patterns with Runx1. Gene Expr Patterns 6: 29-39.

CAPRIOLI, A., JAFFREDO, T., GAUTIER, R., DUBOURG, C. and DIETERLENLIĖVRE, F. (1998). Blood-borne seeding by hematopoietic and endothelial precursors from the allantois. Proc. Natl. Acad. Sci. USA 95: 1641-1646.

CAPRIOLI, A., MINKO, K., DREVON, C., EICHMANN, A., DIETERLEN-LIEVRE, F. and JAFFREDO, T. (2001). Hemangioblast commitment in the avian allantois: cellular and molecular aspects. Dev Bio/238: 64-78.

CHAPMAN, S.C., COLLIGNON, J., SCHOENWOLF, G.C. and LUMSDEN, A. (2001). Improved method for chick whole-embryo culture using a filter paper carrier. Dev Dyn 220: 284-289.

CHEN, M.J., YOKOMIZO, T., ZEIGLER, B.M., DZIERZAK, E. and SPECK, N.A. (2009). Runx1 is required for the endothelial to haematopoietic cell transition but not thereafter. Nature 457: 887-891.

CORBEL, C. (2002). Expression of alphaVbeta3 integrin in the chick embryo aortic endothelium. Int J Dev Bio/46: 827-830.

CORBEL, C., SALAUN, J., BELO-DIABANGOUAYA, P. and DIETERLEN-LIEVRE, F. (2007). Hematopoietic potential of the pre-fusion allantois. Dev Bio/301: 478488.

CORMIER, F. (1993). Avian pluripotent haemopoietic progenitor cells: detection and enrichment from the para-aortic region of the early embryo. J Cel/ Sci105: 661-666.

CORMIER, F., DE PAZ, P. and DIETERLEN-LIEVRE, F. (1986). In vitro detection of cells with monocytic potentiality in the wall of the chick embryo aorta. Dev Biol 118: 167-175.

CORMIER, F. and DIETERLEN-LIEVRE, F. (1988). The wall of the chick embryo aorta harbours M-CFC, G-CFC, GM-CFC and BFU-E. Development 102: 279285.

DE BRUIJN, M., MA, X., ROBIN, C., OTTERSBACH, K., SANCHEZ, M.J. and DZIERZAK, E. (2002). Hematopoietic stem cells localise to the endothelial cell layer in the midgestation mouse aorta. Immunity 16: 673-683.

DIETERLEN-LIEVRE, F. (1975). On the origin of haemopoietic stem cells in the avian embryo: an experimental approach. J Embryol Exp Morpho/33: 607-619.

Dieterlen-LieVRE, F., POUGeT, C., BOllerot, K. and JAFFredo, T. (2006). Are intra-aortic hemopoietic cells derived from endothelial cells during ontogeny? Trends Cardiovasc Med 16: 128-139.

DURAND, C., ROBIN, C., BOLLEROT, K., BARON, M.H., OTTERSBACH, K. and DZIERZAK, E. (2007). Embryonic stromal clones reveal developmental regulators of definitive hematopoietic stem cells. Proc Nat/ Acad Sci USA 104: 2083820843.

EICHMANN, A., CORBEL, C., NATAF, V., VAIGOT, P., BREANT, C. and LE DOUARIN, N.M. (1997). Ligand-dependent development of the endothelial and hemopoietic lineages from embryonic mesodermal cells expressing vascular endothelial growth factor receptor 2. Proc Natl Acad Sci USA 94: 5141-5146.

EILKEN, H.M., NISHIKAWA, S. and SCHROEDER, T. (2009). Continuous singlecell imaging of blood generation from haemogenic endothelium. Nature 457: 896-900.

EMA, M., TAKAHASHI, S. and ROSSANT, J. (2006). Deletion of the selection cassette, but not cis-acting elements, in targeted Flk1-lacZ allele reveals Flk1 expression in multipotent mesodermal progenitors. Blood 107: 111-117.

EMAMBOKUS, N.R. and FRAMPTON, J. (2003). The glycoprotein Ilb molecule is expressed on early murine hematopoietic progenitors and regulates their numbers in sites of hematopoiesis. Immunity 19: 33-45.

ESNER, M., MEILHAC, S.M., RELAIX, F., NICOLAS, J.F., COSSU, G. and BUCKINGHAM, M.E. (2006). Smooth muscle of the dorsal aorta shares a common clonal origin with skeletal muscle of the myotome. Development 133: 737-749.

GARCIA-PORRERO, J.A., GODIN, I.E. and DIETERLEN-LIEVRE, F. (1995). 
Potential intraembryonic hemogenic sites at pre-liver stages in the mouse. Anat Embryol (Berl) 192: 425-35.

GEKAS, C., DIETERLEN-LIEVRE, F., ORKIN, S.H. and MIKKOLA, H.K. (2005). The placenta is a niche for hematopoietic stem cells. Dev Cel/8: 365-375.

GODIN, I.E., GARCIA-PORRERO, J.A., COUTINHO, A., DIETERLEN-LIEVRE, F. and MARCOS, M.A. (1993). Para-aortic splanchnopleura from early mouse embryos contains B1a cell progenitors. Nature 364: 67-70.

JAFFREDO, T., BOLLEROT, K., SUGIYAMA, D., GAUTIER, R. and DREVON, C. (2005). Tracing the hemangioblast during embryogenesis: developmental relationships between endothelial and hematopoietic cells. Int J Dev Bio/49: 269277.

JAFFREDO, T., GAUTIER, R., BRAJEUL, V. and DIETERLEN-LIEVRE, F. (2000). Tracing the progeny of the aortic hemangioblast in the avian embryo. Dev Biol 224: 204-214.

JAFFREDO, T., GAUTIER, R., EICHMANN, A. and DIETERLEN-LIEVRE, F. (1998). Intraaortic hemopoietic cells are derived from endothelial cells during ontogeny. Development 125: 4575-4583.

JEURISSEN, S.H. and JANSE, E.M. (1998). The use of chicken-specific antibodies in veterinary research involving three other avian species. Vet Q20: 140-143.

JORDAN, H.E. (1916). Evidence of hemogenic capacity of endothelium. The Anatomical Record 10: 417-420.

KYBA, M. and DALEY, G.Q. (2003). Hematopoiesis from embryonic stem cells: lessons from and for ontogeny. Exp Hemato/31: 994-1006.

LACAUD, G., KELLER, G. and KOUSKOFF, V. (2004). Tracking mesoderm formation and specification to the hemangioblast in vitro. Trends Cardiovasc Med 14: 314-317.

LACAUD, G., ROBERTSON, S., PALIS, J., KENNEDY, M. and KELLER, G. (2001). Regulation of hemangioblast development. Ann N Y Acad Sci 938: 96-107; discussion 108.

LANCRIN, C., SROCZYNSKA, P., STEPHENSON, C., ALLEN, T., KOUSKOFF, V. and LACAUD, G. (2009). The haemangioblast generates haematopoietic cells through a haemogenic endothelium stage. Nature 457: 892-895.

LASSILA, O., ESKOLA, J., TOIVANEN, P. and DIETERLEN-LIEVRE, F. (1980). Lymphoid stem cells in the intraembryonic mesenchyme of the chicken. Scand $J$ Immuno/ 11: 445-448.

LASSILA, O., ESKOLA, J., TOIVANEN, P., MARTIN, C. and DIETERLEN-LIEVRE, F. (1978). The origin of lymphoid stem cells studied in chick yolk sac-embryo chimaeras. Nature 272: 353-354.

LASSILA, O., MARTIN, C., DIETERLEN-LIEVRE, F., NURMI, T.E., ESKOLA, J. and TOIVANEN, P. (1979). Is the yolk sac the primary origin of lymphoid stem cells? Transplant Proc 11: 1085-1088.

LASSILA, O., MARTIN, C., TOIVANEN, P. and DIETERLEN-LIEVRE, F. (1982). Erythropoiesis and lymphopoiesis in the chick yolk-sac-embryo chimeras: contribution of yolk sac and intraembryonic stem cells. Blood59: 377-381.

LE DOUARIN, N. (1969). Details of the interphase nucleus in Japanese quail (Coturnix coturnix japonica). Bull Biol Fr Belg 103: 435-452.

MANAIA, A., LEMARCHANDEL, V., KLAINE, M., MAX-AUDIT, I., ROMEO, P., DIETERLEN-LIEVRE, F. and GODIN, I. (2000). Lmo2 and GATA-3 associated expression in intraembryonic hemogenic sites. Development 127: 643-653.

MARSHALL, C.J., MOORE, R.L., THOROGOOD, P., BRICKELL, P.M., KINNON, C. and THRASHER, A.J. (1999). Detailed characterization of the human aortagonad-mesonephros region reveals morphological polarity resembling a hematopoietic stromal layer. Dev Dyn 215: 139-147.

MARTIN, C. (1972). Technique d'explantation in ovo de blastodermes d'embryons d'oiseaux. C. R. Seances Soc. Biol. (Paris) 166: 283-285.

MARTIN, C., BEAUPAIN, D. and DIETERLEN-LIEVRE, F. (1978). Developmental relationships between vitelline and intra-embryonic haemopoiesis studied in avian 'yolk sac chimaeras'. Cell Differ7: 115-130.

MARTIN, C., LASSILA, O., NURMI, T., ESKOLA, J., DIETERLEN-LIEVRE, F. and TOIVANEN, P. (1979). Intraembryonic origin of lymphoid stem cells in the chicken: studies with sex chromosome and IgG allotype markers in histocompatible yolk sac-embryo chimaeras. Scand J Immunol 10: 333-338.

MEDVINSKY, A.L., SAMOYLINA, N.L., MULLER, A.M. and DZIERZAK, E.A. (1993). An early pre-liver intraembryonic source of CFU-S in the developing mouse. Nature 364: 64-67.
MIKKOLA, H.K., FUJIWARA, Y., SCHLAEGER, T.M., TRAVER, D. and ORKIN, S.H. (2003). Expression of CD41 marks the initiation of definitive hematopoiesis in the mouse embryo. Blood 101: 508-516.

MOORE, M.A. and OWEN, J.J. (1965). Chromosome marker studies on the development of the haemopoietic system in the chick embryo. Nature 208: 956 passim.

MOORE, M.A. and OWEN, J.J. (1967a). Chromosome marker studies in the irradiated chick embryo. Nature 215: 1081-1082.

MOORE, M.A. and OWEN, J.J. (1967b). Experimental studies on the development of the thymus. $J$ Exp Med 126: 715-726.

NODEN, D.M. (1989). Embryonic origins and assembly of blood vessels. Am Rev Respir Dis 140: 1097-1103.

ODY, C., VAIGOT, P., QUERE, P., IMHOF, B.A. and CORBEL, C. (1999). Glycoprotein Illb-IIla is expressed on avian multilineage hematopoietic progenitor cells. Blood 93: 2898-2906.

OOSTENDORP, R.A., HARVEY, K.N., KUSADASI, N., DE BRUIJN, M.F., SARIS, C., PLOEMACHER, R.E., MEDVINSKY, A.L. and DZIERZAK, E.A. (2002a). Stromal cell lines from mouse aorta-gonads-mesonephros subregions are potent supporters of hematopoietic stem cell activity. Blood99: 1183-1189.

OOSTENDORP, R.A., MEDVINSKY, A.J., KUSADASI, N., NAKAYAMA, N., HARVEY, K., ORELIO, C., OTTERSBACH, K., COVEY, T., PLOEMACHER R.E., SARIS, C. et al. (2002b). Embryonal subregion-derived stromal cell lines from novel temperature-sensitive SV40 T antigen transgenic mice support hematopoiesis. J Cell Sci115: 2099-2108.

OOSTENDORP, R.A., ROBIN, C., STEINHOFF, C., MARZ, S., BRAUER, R., NUBER, U.A., DZIERZAK, E.A. and PESCHEL, C. (2005). Long-term maintenance of hematopoietic stem cells does not require contact with embryo-derived stromal cells in cocultures. Stem Cells 23: 842-851.

OTTERSBACH, K. and DZIERZAK, E. (2005). The murine placenta contains hematopoietic stem cells within the vascular labyrinth region. Dev Cel/8: 377387.

PARDANAUD, L., ALTMANN, C., KITOS, P., DIETERLEN-LIEVRE, F. and BUCK, C.A. (1987). Vasculogenesis in the early quail blastodisc as studied with a monoclonal antibody recognizing endothelial cells. Development100: 339-349.

PARDANAUD, L. and DIETERLEN-LIEVRE, F. (1993). Emergence of endothelial and hemopoietic cells in the avian embryo. Anat Embryol(Berl) 187: 107-114.

PARDANAUD, L. and DIETERLEN-LIEVRE, F. (1999). Manipulation of the angiopoietic/hemangiopoietic commitment in the avian embryo. Development 126: 617-627.

PARDANAUD, L., LUTON, D., PRIGENT, M., BOURCHEIX, L.-M., CATALA, M and DIETERLEN-LIĖVRE, F. (1996). Two distinct endothelial lineages in ontogeny, one of them related to hemopoiesis. Development 122: 1363-1371.

PARDANAUD, L., YASSINE, F. and DIETERLEN-LIEVRE, F. (1989). Relationship between vasculogenesis, angiogenesis and haemopoiesis during avian ontogeny. Development 105: 473-485.

POUGET, C., GAUTIER, R., TEILLET, M.A. and JAFFREDO, T. (2006). Somitederived cells replace ventral aortic hemangioblasts and provide aortic smooth muscle cells of the trunk. Development 133: 1013-1022.

POUGET, C., POTTIN, K. and JAFFREDO, T. (2008). Sclerotomal origin of vascular smooth muscle cells and pericytes in the embryo. Dev Bio/315: 437447.

PUDLISZEWSKI, M. and PARDANAUD, L. (2005). Vasculogenesis and angiogenesis in the mouse embryo studied using quail/mouse chimeras. IntJ DevBio/49: 355-361.

RISAU, W. and LEMMON, V. (1988). Changes in the vascular extracellular matrix during embryonic vasculogenesis and angiogenesis. Dev Bio/125: 441-450.

ROBIN, C., BOLLEROT, K., MENDES, S., HAAK, E., CRISAN, M., CERISOLI, F., LAUW, I., KAIMAKIS, P., JORNA, R., VERMEULEN, M. et al. (2009). Human placenta is a potent hematopoietic niche containing hematopoietic stem and progenitor cells throughout development. Cel/ Stem Cel/5: 385-395.

ROBIN, C. and DURAND, C. (2010). The roles of BMP and IL-3 signaling pathways in the control of hematopoietic stem cells in the mouse embryo. Int. J. Dev. Biol. 54: 1189-1200. (doi: 10.1387/ijdb.093040cr).

SASSOON, D.A., GARNER, I. and BUCKINGHAM, M. (1988). Transcripts of alphacardiac and alpha-skeletal actins are early markers for myogenesis in the 
mouse embryo. Development 104: 155-164.

SATO, Y., WATANABE, T., SAITO, D., TAKAHASHI, T., YOSHIDA, S., KOHYAMA, J., OHATA, E., OKANO, H. and TAKAHASHI, Y. (2008). Notch mediates the segmental specification of angioblasts in somites and their directed migration toward the dorsal aorta in avian embryos. Dev Cel/14: 890-901.

TAOUDI, S. and MEDVINSKY, A. (2007). Functional identification of the hematopoietic stem cell niche in the ventral domain of the embryonic dorsal aorta. Proc Natl Acad Sci USA 104: 9399-9403.

TAVIAN, M., COULOMBEL, L., LUTON, D., SAN CLEMENTE, H., DIETERLENLIĖVRE, F. and PEAULT, B. (1996). Aorta-associated CD34 ${ }^{+}$hematopoietic cells in the early human embryo. Blood 87: 67-72.

WANG, L., LI, L., SHOJAEI, F., LEVAC, K., CERDAN, C., MENENDEZ, P., MARTIN, T., ROULEAU, A. and BHATIA, M. (2004). Endothelial and hematopoietic cell fate of human embryonic stem cells originates from primitive endothelium with hemangioblastic properties. Immunity 21: 31-41.

WASTESON, P., JOHANSSON, B.R., JUKKOLA, T., BREUER, S., AKYUREK, L.M., PARTANEN, J. and LINDAHL, P. (2008). Developmental origin of smooth muscle cells in the descending aorta in mice. Development 135: 1823-1832.

WIEGREFFE, C., CHRIST, B., HUANG, R. and SCAAL, M. (2007). Sclerotomal origin of smooth muscle cells in the wall of the avian dorsal aorta. Dev Dyn236:
2578-2585.

WIEGREFFE, C., CHRIST, B., HUANG, R. and SCAAL, M. (2009). Remodeling of aortic smooth muscle during avian embryonic development. Dev Dyn238: 624631.

WILTING, J., KURZ, H., BRAND-SABERI, B., STEDING, G., YANG, Y.X., HASSELHORN, H.M., EPPERLEIN, H.H. and CHRIST, B. (1994). Kinetics and differentiation of somite cells forming the vertebral column: studies on human and chick embryos. Anat Embryol (Berl) 190: 573-581.

WOOD, H.B., MAY, G., HEALY, L., ENVER, T. and MORRISS-KAY, G.M. (1997). CD34 expression patterns during early mouse development are related to modes of blood vessel formation and reveal additional sites of hematopoiesis. Blood 90: 2300-2311.

ZEIGLER, B.M., SUGIYAMA, D., CHEN, M., GUO, Y., DOWNS, K.M. and SPECK, N.A. (2006). The allantois and chorion, when isolated before circulation or chorio-allantoic fusion, have hematopoietic potential. Development 133: 41834192.

ZOVEIN, A.C., HOFMANN, J.J., LYNCH, M., FRENCH, W.J., TURLO, K.A., YANG, Y., BECKER, M.S., ZANETTA, L., DEJANA, E., GASSON, J.C. et al. (2008). Fate tracing reveals the endothelial origin of hematopoietic stem cells. Cell Stem Cel/3: 625-636. 


\section{Further Related Reading, published previously in the Int. J. Dev. Biol.}

See our recent Special Issue Placenta edited by Joan S. Hunt and Kent L. Thornburg at: http://www.ijdb.ehu.es/web/contents.php?vol=54\&issue=2-3

Dynamic expression of Endoglin, a TGF-beta co-receptor, during pre-circulation vascular development in chick Cantas Alev, Brendan A.S. McIntyre, Kanako Ota and Guojun Sheng Int. J. Dev. Biol. (2010) 54: 737-742 (doi: 10.1387/ijdb.092962ca)

Ontogeny of an adventurous mind: the origin of Antonio García-Bellido's contributions to developmental genetics Alain Ghysen

Int. J. Dev. Biol. (2009) 53: 1277-1290

Epiblast-derived stem cells in embryonic and adult tissues

Maria P. De-Miguel, Francisco Arnalich-Montiel, Pilar Lopez-Iglesias, Alejandro Blazquez-Martinez and Manuel Nistal

Int. J. Dev. Biol. (2009) 53: 1529-1540

A novel role of the glial fate determinant glial cells missing in hematopoiesis Cécile Jacques, Laurent Soustelle, István Nagy, Céline Diebold and Angela Giangrande Int. J. Dev. Biol. (2009) 53: 1013-1022

Developmentally regulated expression of hemoglobin subunits in avascular tissues Fiona C. Mansergh, Susan M. Hunter, Jenny C. Geatrell, Miguel Jarrin, Kate Powell, Martin J. Evans and Michael A. Wride Int. J. Dev. Biol. (2008) 52: 873-886

Embryonic development of the proepicardium and coronary vessels Anna Ratajska, Elzbieta Czarnowska and Bogdan Ciszek Int. J. Dev. Biol. (2008) 52: 229-236

Early mammalian embryo: my love. An interview with Andrzej K. Tarkowski Marek Maleszewski and Andrzej K. Tarkowski Int. J. Dev. Biol. (2008) 52: 163-169

Interleukin-2 induces the proliferation of mouse primordial germ cells in vitro Cristina Eguizabal, Maria D. Boyano, Alejandro Díez-Torre, Ricardo Andrade, Noelia Andollo, Massimo De Felici and Juan Aréchaga

Int. J. Dev. Biol. (2007) 51: 731-738

Tracing the hemangioblast during embryogenesis: developmental relationships between endothelial and hematopoietic cells

Thierry Jaffredo, Karine Bollerot, Daisuke Sugiyama, Rodolphe Gautier and Cécile Drevon Int. J. Dev. Biol. (2005) 49: 269-277

Of birds and mice: hematopoietic stem cell development Isabelle Godin and Ana Cumano Int. J. Dev. Biol. (2005) 49: 251-257

Embryonic development of the human hematopoietic system Manuela Tavian and Bruno Péault Int. J. Dev. Biol. (2005) 49: 243-250

Multilineage hematopoietic progenitor activity generated autonomously in the mouse yolk sac: analysis using angiogenesis-defective embryos Christine Rampon and Philippe Huber Int. J. Dev. Biol. (2003) 47: 273-280

Polyembryony in parasitic wasps: evolution of a novel mode of development Miodrag Grbic Int. J. Dev. Biol. (2003) 47: 633-642

Pathways in blood and vessel development revealed through zebrafish genetics Philip S Crosier, Maggie L Kalev-Zylinska, Christopher J Hall, Maria Vega C Flores, Julia A Horsfield and Kathryn E Crosier Int. J. Dev. Biol. (2002) 46: 493-502

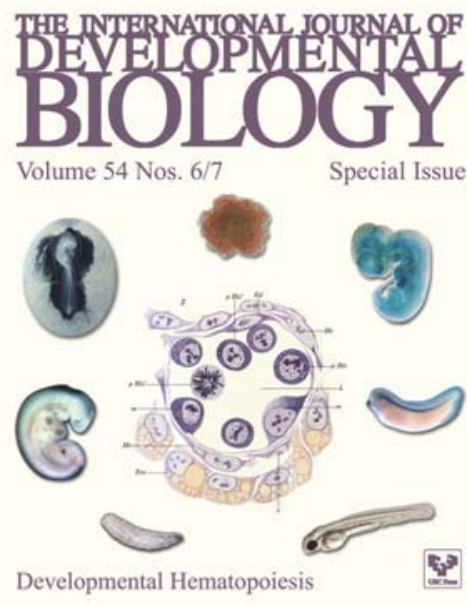

ISI Impact Factor $(2010)=2.86$

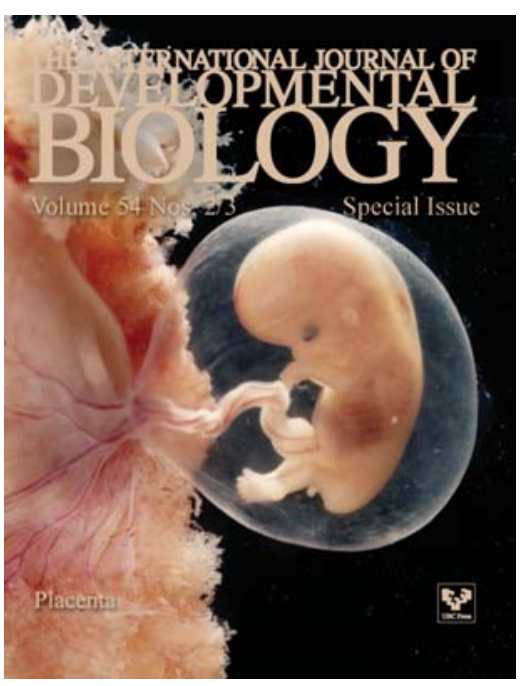

